\title{
EFICIENCIA DE CEBOS COMO ATRAYENTES DE MOSCAS DE LA FRUTA EN EL SALVADOR ${ }^{1}$
}

\author{
Muriel Delmi ${ }^{2}$, Salvador Morán ${ }^{2}$, Fernando Núñez ${ }^{2}$, Gilberto Granados ${ }^{3}$
}

\begin{abstract}
RESUMEN
Eficiencia de cebos como atrayentes de moscas de la fruta en EI Salvador. Con el objetivo de determinar el cebo alimenticio más eficiente para aumentar la capacidad de captura de adultos de especies de Moscas de la Fruta y encontrar una alternativa a la proteína hidrolizada, se desarrolló el presente estudio en la Finca Maraví, Planes de Renderos, Departamento de San Salvador a 930 msnm. El diseño empleado fue bloques completamente al azar con cinco tratamientos y cuatro repeticiones. Se utilizó la trampa de vidrio tipo McPhail. La eficiencia de los tratamientos se midió con base al índice de captura Moscas/trampa/día (MTD). Hubo diferencias estadísticas significativas: el jugo de naranja fue el atrayente alimenticio más eficiente, capturando un promedio de seis veces más moscas de la fruta que la proteína hidrolizada. La urea más melaza resultaron con índices de captura altos, siendo iguales estadísticamente que la proteína hidrolizada. Los resultados obtenidos indican que los atrayentes alimenticios podrían ser parte importante dentro de un manejo integrado de moscas de la fruta.
\end{abstract}

\begin{abstract}
The efficiency of bait to attract fruit flies in El Salvador. With the goal of determining the most efficient food bait for augmenting the capacity to capture adults of some species of fruit flies and also to find an alternative to hidrolized protein, this research project took place in "Finca Maravi", in Planes de Renderos, Department of San Salvador, a $930 \mathrm{msnm}$. The design which was used was the one with randomly located blocks with five treatments and four repetitions. The McPhail glass trap was utilized. The efficiency of treatments was determined by the amount of captured flies, by trap, by day (F.T.D). The analyses indicated significant differences among them, but it was observed that orange juice is the most efficient food bait, capturing an average of six times more fruit flies than hidrolized protein. Urea with molasses also rendered high capture yields, statistically equal to those of hidrolized protein. The results which were obtained, indicated that food bait could play an important role in the integrated management of fruit flies.
\end{abstract}

\section{INTRODUCCION}

Las moscas de la fruta del género Anastrepha, son una plaga de importancia económica en El Salvador,(El Salvador, Dirección General de Sanidad Vegetal y Animal, 1994 y 1995) y en muchos países de América Tropical, tanto por el daño directo que ocasiona dentro de los frutos como por las estrictas barreras cuarentenarias que impiden su comercialización a los mercados de exportación libres de esta plaga, (Centro Internacional de Capacitación en moscas de la fruta 1992 y 1993).

Para llevar con éxito un programa de Manejo Integrado de Moscas de las Frutas y disminuir las poblaciones y pérdidas en la producción frutícola, se ne- cesita conocer la fluctuación poblacional de especies de mayor impacto comercial. Una de las principales actividades de detección de moscas adultas es la utilización de trampas cebadas con atrayentes alimenticios, (Bustillo, Londoño y López, 1989. El potencial que tienen algunos atrayentes no ha sido estudiado en forma suficiente en el país.

El número de moscas de la fruta capturadas en un sistema de trampeo, depende principalmente de los atrayentes alimenticios utilizados. En el presente trabajo se evaluó la efectividad de productos considerados como atrayentes alimenticios de estas moscas a fin de mejorar la eficiencia de captura y encontrar una alternativa a la proteína hidrolizada el cual es el atrayente alimenticio

\footnotetext{
1 Presentado en la XLI Reunión Anual del PCCMCA en Honduras, América Central. 26 de marzo - 1 de abril, 1995.

2 Programa de Sanidad Vegetal, DGSVA, Ministerio de Agricultura y Ganadería, El Salvador.

3 Programa de Sanidad Vegetal, DGSVA, Ministerio de Agricultura y Ganadería, El Salvador.
} 
más utilizado a nivel mundial, pero que en la actualidad no se encuentra en el mercado local.

\section{MATERIALES Y METODOS}

El estudio se realizó de mayo a julio de 1994, su localización fue en la finca Maraví, Cantón Planes de Renderos en el Departamento de San Salvador, a una altura de $930 \mathrm{msnm}$, una temperatura y una precipitación media anual de $23{ }^{\circ} \mathrm{C}$ y $1754 \mathrm{~mm}$, respectivamente, con vientos dominantes del norte. Cuenta con una superficie de siete hectáreas de cítricos : Naranja dulce (Citrus sinensis ) de las variedades, Washington, Navel, Jaffa, Victoria y criolla y mandarina (Citrus reticulata) varie-dades : Dancy, Roja , Kent, Satsuma y criolla. También hay árboles de guayaba (Psidium guajaba), granada (Punica granatum), caimito (Chrysophillum cainito) y níspero japonés (Eriobotria japonica) y carambola (Aberrhoa carambola).

Se empleó el diseño experimental de bloques completos al azar con cinco tratamientos y cuatro repeticiones. Se utilizaron trampas de vidrio McPhail. Cada tratamiento tuvo cuatro trampas, colocadas en árboles de cítricos en un área de 42 m x 78 m ( 0,33 hectáreas) en un grupo de 90 árboles.
En cada trampa se adicionaron $250 \mathrm{ml}$. de la mezcla de los cuatro atrayentes por evaluar más proteínas hidrolizadas, como testigo (Cuadro 1) y se ubicó la trampa a 3/4 partes de la altura del árbol.

Cada siete días se cambió el atrayente de las trampas por nueva mezcla, efectuándose el recuento por sexo de moscas capturadas, las cuales se colocaban con su respectiva clave en tubos de ensayo conteniendo alcohol 70 por ciento, para su posterior identificación en el Laboratorio de Taxonomía del Programa de Sanidad Vegetal, para lo que se utilizaron las claves taxonómicas de Korytkowski.

Para la comparación entre los tratamientos se usó el índice de captura conocido por MTD y se calculó mediante la siguiente relación:

$$
\mathrm{MTD}=\frac{\mathrm{M}}{\mathrm{TD}}
$$

$$
\begin{aligned}
\text { MTD }= & \text { Moscas } / \text { Trampa } / \text { Día } \\
\mathrm{M}= & \mathrm{N}^{\circ} \cdot \text { de Moscas Capturadas } \\
\mathrm{T}= & \mathrm{N}^{\circ} \cdot \text { de trampas revisadas } \\
\mathrm{D}= & \mathrm{N}^{\circ} \text { de días que las trampas estuvieron } \\
& \text { expuestas. }
\end{aligned}
$$

Cuadro 1. Atrayentes alimenticios y dosis evaluadas para una y cuatro trampas tipo McPHAIL. Finca Maravi, El Salvador. Mayo - Julio, 1994.

\begin{tabular}{lll}
\hline $\begin{array}{c}\text { Tratamiento } \\
\text { (trampa) }\end{array}$ & Ingredientes & Dosis/trampa \\
$\mathbf{T} 1$ & Urea $\mathbf{~ m ~ d e ~ a g u a ~}$ \\
& Melaza & 5 gramos \\
& Bórax & 5 ml \\
T2* & Jugo de Naranja & 5 gramos \\
& Bórax & 250 ml. \\
T3 & Sulfato de Amonio & 5 gramos \\
& Melaza & 10 gramos \\
& Bórax & 5 ml. \\
T4 (Testigo) & Proteína Hidrolizada (Líquida) & 5 gramos \\
& Bórax & 15 ml. \\
T5 $* *$ & MOX & 5 gramos \\
\hline
\end{tabular}

$\mathrm{T} 2 * \quad$ No se mezcla con agua

T5 ** Ingredientes (Proteína, sal, tetraborato de sodio,socenosa). 


\section{RESULTADOS Y DISCUSION}

Se observaron diferencias altamente significativa entre tratamientos a partir de la segunda semana. El promedio de moscas capturadas por día, moscas capturadas por semana y hembras y machos capturados por tratamiento, durante un período de 10 semanas, representa en el Cuadro 2. Hubo una diferencia altamente significativa entre tratamientos, donde el jugo de naranja superó al resto de tratamientos, obteniendo un promedio mayor del número de moscas capturadas/día; por semana y por sexo.

Del total de moscas que se capturaron durante el período que duró el estudio 3613 moscas fueron captu- radas con jugo de naranja (Figura 1), lo que constituyó el $62,4 \%$ de capturas (Figura 2).

Los otros cuatro atrayentes evaluados resultaron estadísticamente iguales entre si, pero numéricamente se observa que la respuesta a la atracción estuvo en el siguiente orden: Proteína Hidrolizada (testigo) $>$ Urea $>$ MOX $>$ Sulfato de Amonio (Figura 2). Lo anterior indica la superioridad del jugo de naranja como atrayente de moscas de la fruta; posiblemente el color amarillo y su olor característico sea un buen estimulante de alimentación para la plaga.

La captura con los diferentes tratamientos fue tanto para hembras como machos (Cuadro 3); favoreciendo la

Cuadro 2. Total de moscas, moscas por día, hembras y machos capturados durante 10 semanas. Finca Maravi. El Salvador. mayo - julio, 1994.

\begin{tabular}{lrcrc}
\hline \multirow{2}{*}{ Tratamiento } & \multicolumn{4}{c}{ Número de moscas capturadas } \\
\cline { 2 - 5 } & por día & total/semana & hembras & machos \\
\hline Jugo de naranja & $12,4 \mathrm{a}$ & $90,3 \mathrm{a}$ & $46,7 \mathrm{a}$ & $43,6 \mathrm{a}$ \\
Proteína hidrolizada (líquida) & $2,3 \mathrm{~b}$ & $18,7 \mathrm{~b}$ & $11,3 \mathrm{~b}$ & $7,8 \mathrm{~b}$ \\
Urea + melaza & $2,1 \mathrm{~b}$ & $16,8 \mathrm{~b}$ & $10,0 \mathrm{~b}$ & $6,7 \mathrm{~b}$ \\
Mox & $1,4 \mathrm{~b}$ & $11,1 \mathrm{~b}$ & $6,6 \mathrm{~b}$ & $5,4 \mathrm{~b}$ \\
Sulfato de amonio + melaza & $0,9 \mathrm{~b}$ & $7,0 \mathrm{~b}$ & $4,4 \mathrm{~b}$ & $2,6 \mathrm{~b}$ \\
\hline
\end{tabular}

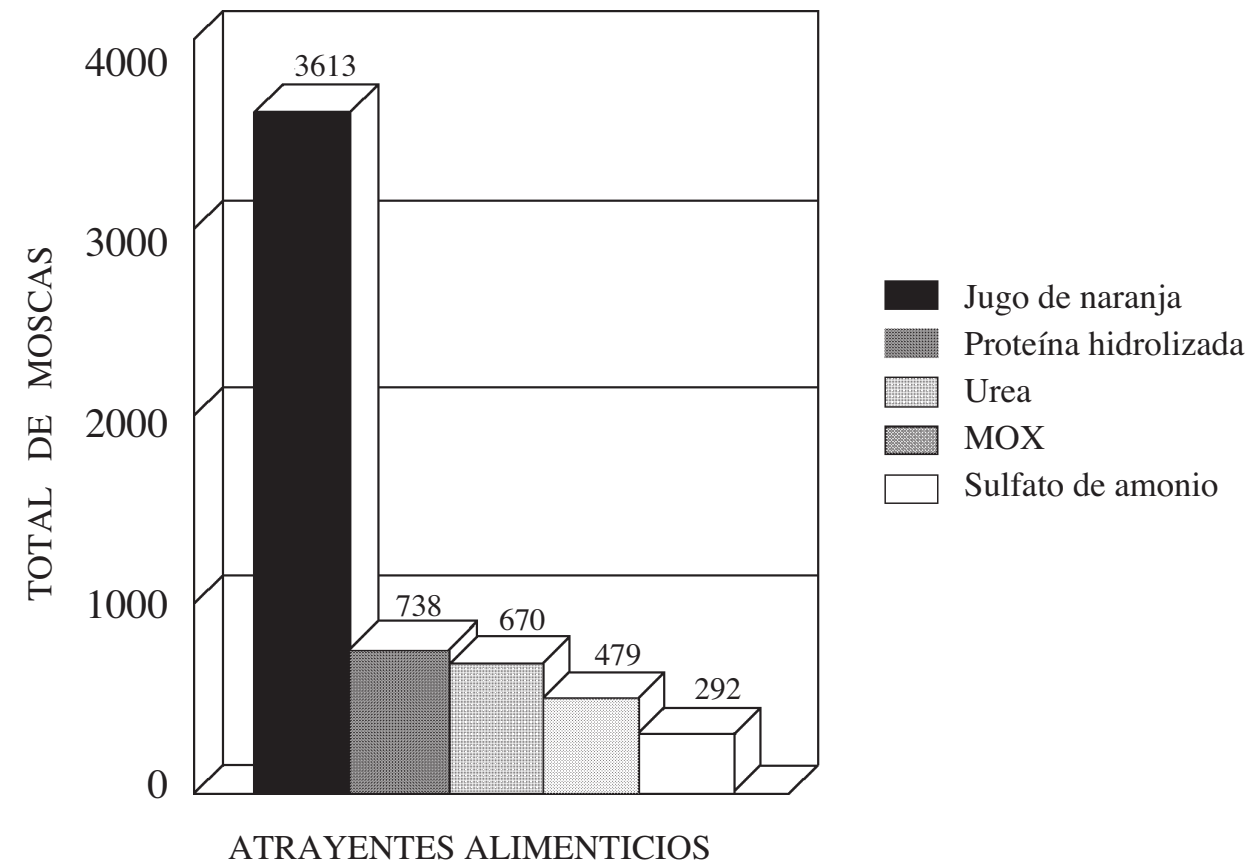

Fig. 1. Captura total de Anastrepha spp. con atrayentes alimenticios durante 10 semanas Fca. Maravi. El Salvador. mayo-julio 94 


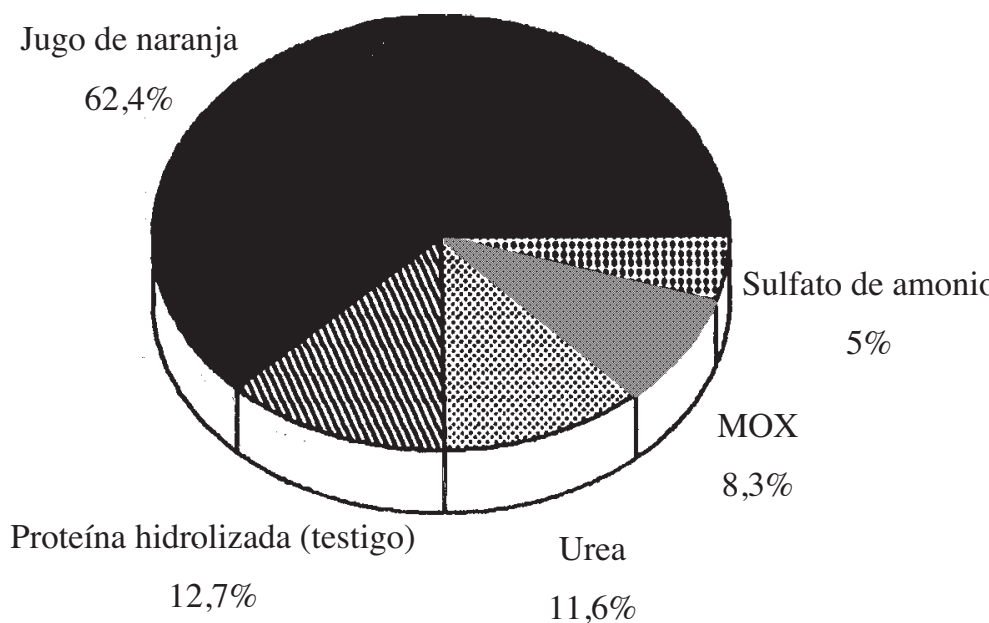

Fig. 2. Porcentaje del número total de Anastrepha spp. con cinco atrayentes alimenticios. Fca. Maravi. El Salvador. MayoJulio 94.

Cuadro 3. Relación Hembra/Macho de Anastrepha spp, capturados con los diferentes atrayentes. Finca Maravi, El Salvador. Mayo - Julio, 1994.

\begin{tabular}{lrrr}
\hline Atrayentes & \multicolumn{2}{c}{ Número de moscas } & Relación \\
\cline { 2 - 3 } & Hembra & Macho & Hembra/Macho \\
\hline Urea & 401 & 296 & $1,49 / 1$ \\
Jugo de naranja & 1869 & 1744 & $1,07 / 1$ \\
Sulfato de Amonio & 187 & 105 & $1,78 / 1$ \\
Proteína Hidrolizada (líquida) & 429 & 314 & $1,35 / 1$ \\
MOX & 262 & 217 & $1,21 / 1$ \\
\hline Total & 3143 & 2649 & $1,19 / 1$ \\
\hline
\end{tabular}

captura de hembras en un promedio de 1,19 hembras : 1 macho. La mayor relación se encontró con sulfato de amonio seguido de urea, posiblemente el nitrógeno que contienen estos productos actúa como un atrayente para la hembra, ya que según Aluja (1993) la hembra necesita ingerir mayores cantidades de sustancias nutricionales para realizar sus diferentes actividad reproductivas.

El número de especies de Anastrepha capturadas con los diferentes atrayentes se muestra en las Figuras $3,4,5,6$ y 7 . Con el jugo de naranja se capturaron las siguientes especies : ludens, obliqua, distincta, striata, serpentina, fraterculus chiclayae y sagittata; con proteína hidrolizada se capturaron siete especies, seguida de urea ( seis especies), sulfato de amonio (cinco especies) y mox ( cuatro especies).
Los mayores M.T.D. se obtuvieron con jugo de naranja en las especies ludens ( MTD :5,7), obliqua (MTD : 3,2) y distincta (MTD :3,3), debiéndose esto posiblemente a que las trampas se colocaron en árboles de cítricos, siendo esta fruta una de los hospederos preferidos para la primera especie. A. ludens siempre fue la especie predominante también en los otros cuatro atrayentes, seguida de A. obliqua.

Los valores semanales de las capturas diarias de Anastrepha spp, se aprecia en las Figuras 8, 9, 10,11 y 12.

Con el jugo de naranja se capturó en promedio mayor número de moscas/día en relación con los demás atrayentes. Las capturas fueron aumentando semanalmente, obteniéndose valores muy altos hasta la 


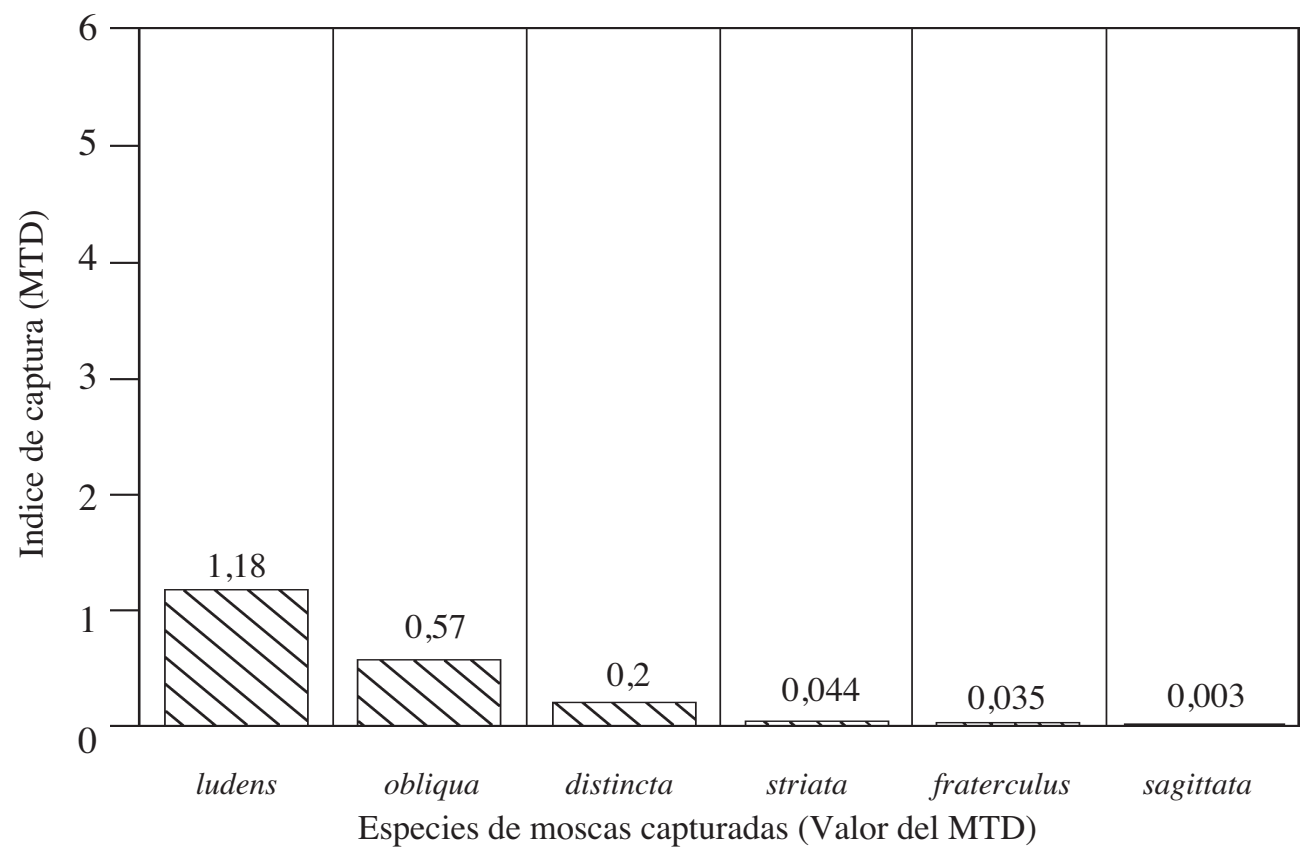

Fig. 3. Promedio de las especies de Anastrepha, capturadas por día, con urea. Fca. Maravi. El Salvador. mayo-julio 94

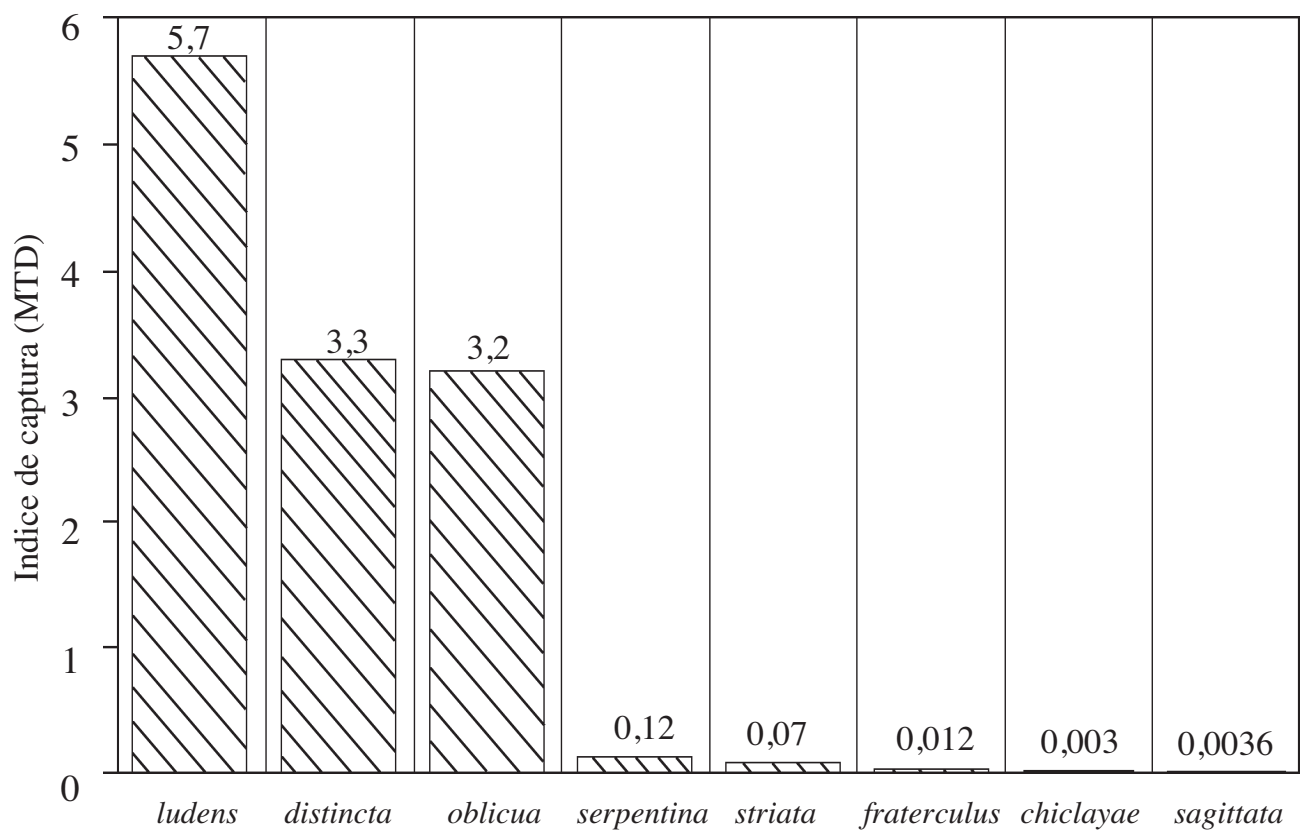

Especies de moscas capturadas

Fig. 4. Promedio de las especies de Anastrepha, capturadas por día, con jugo de naranja. Fca. Maravi. El Salvador. mayo-julio 94. 


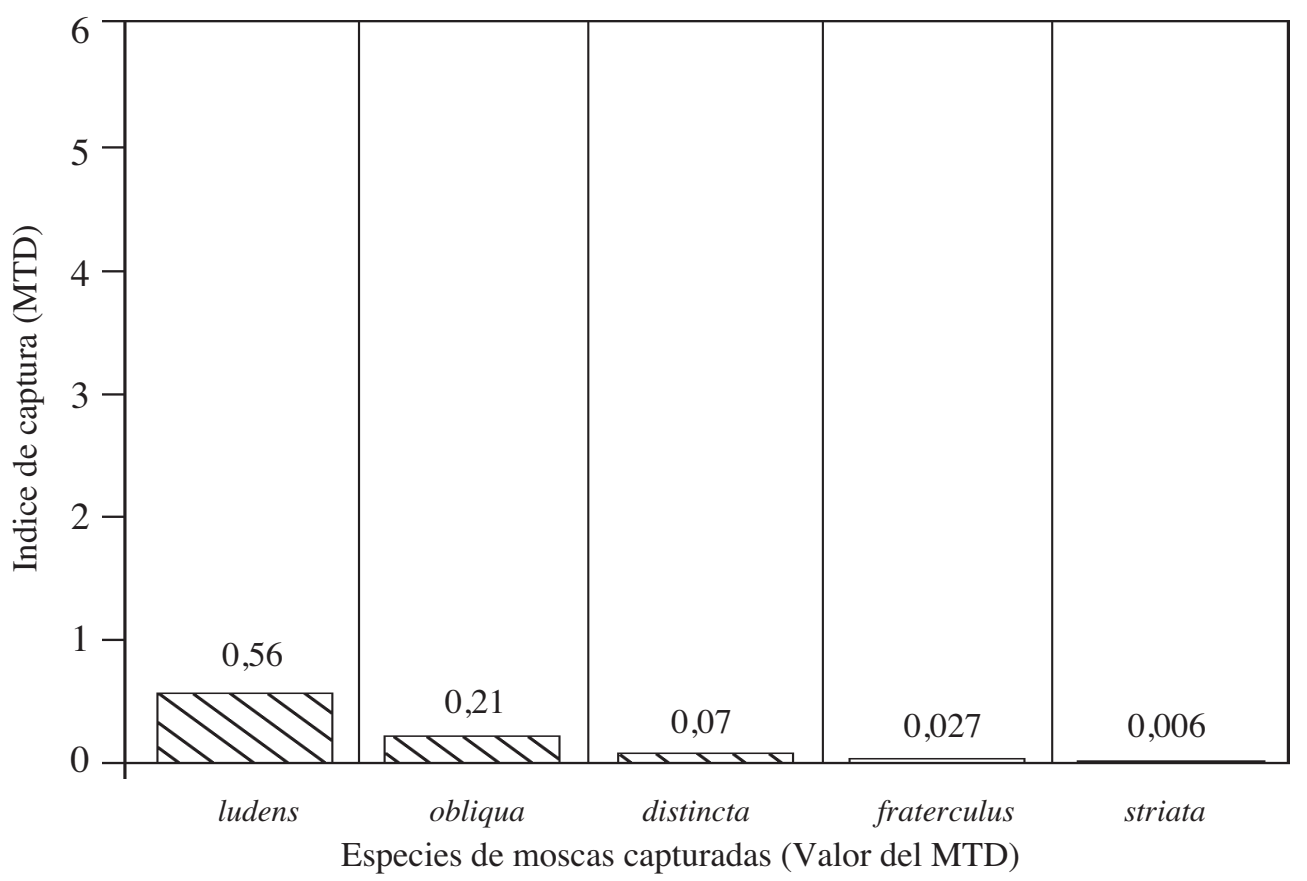

Fig. 5. Promedio de las especies de Anastrepha, capturadas por día, con Sulfato de Amonio. Fca. Maravi. El Salvador. mayo-julio 94

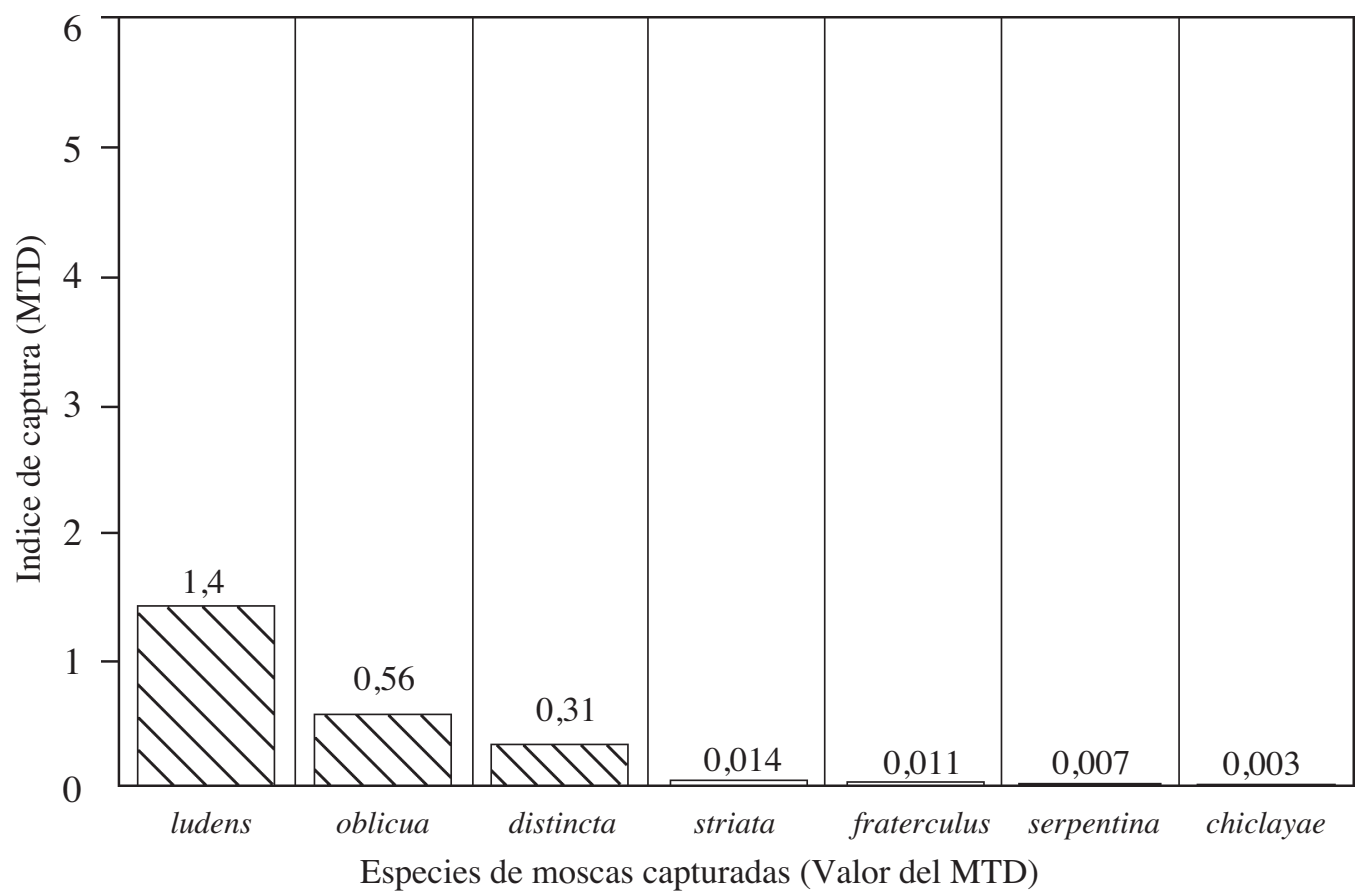

Fig. 6. Promedio de las especies de Anastrepha, capturadas por día, con proteína hidrolizada. Fca. Maravi. El Salvador. mayo-julio 94. 


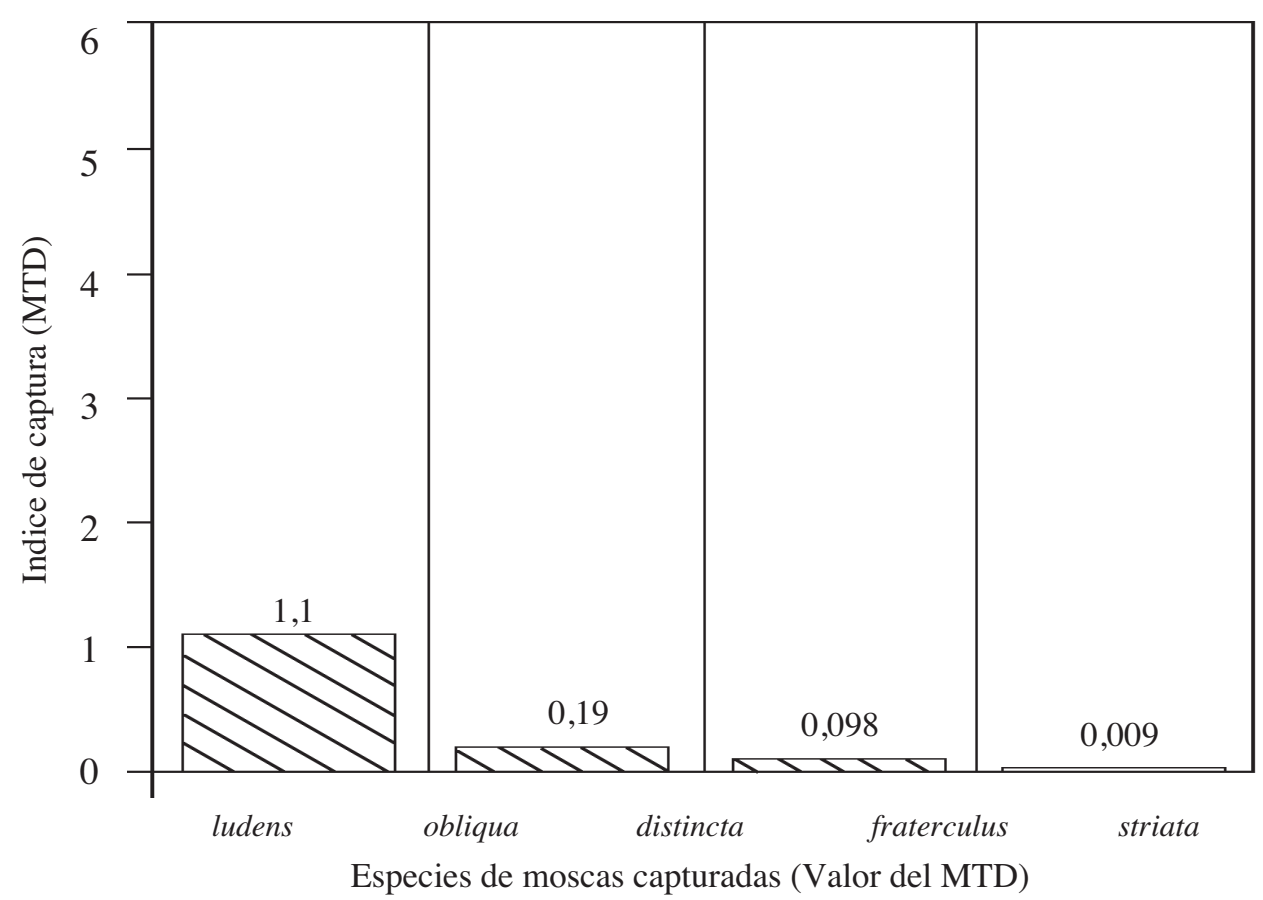

Fig. 7. Promedio de las especies de Anastrepha, capturadas por día, con MOX. Fca. Maravi. El Salvador. mayo-julio 94.

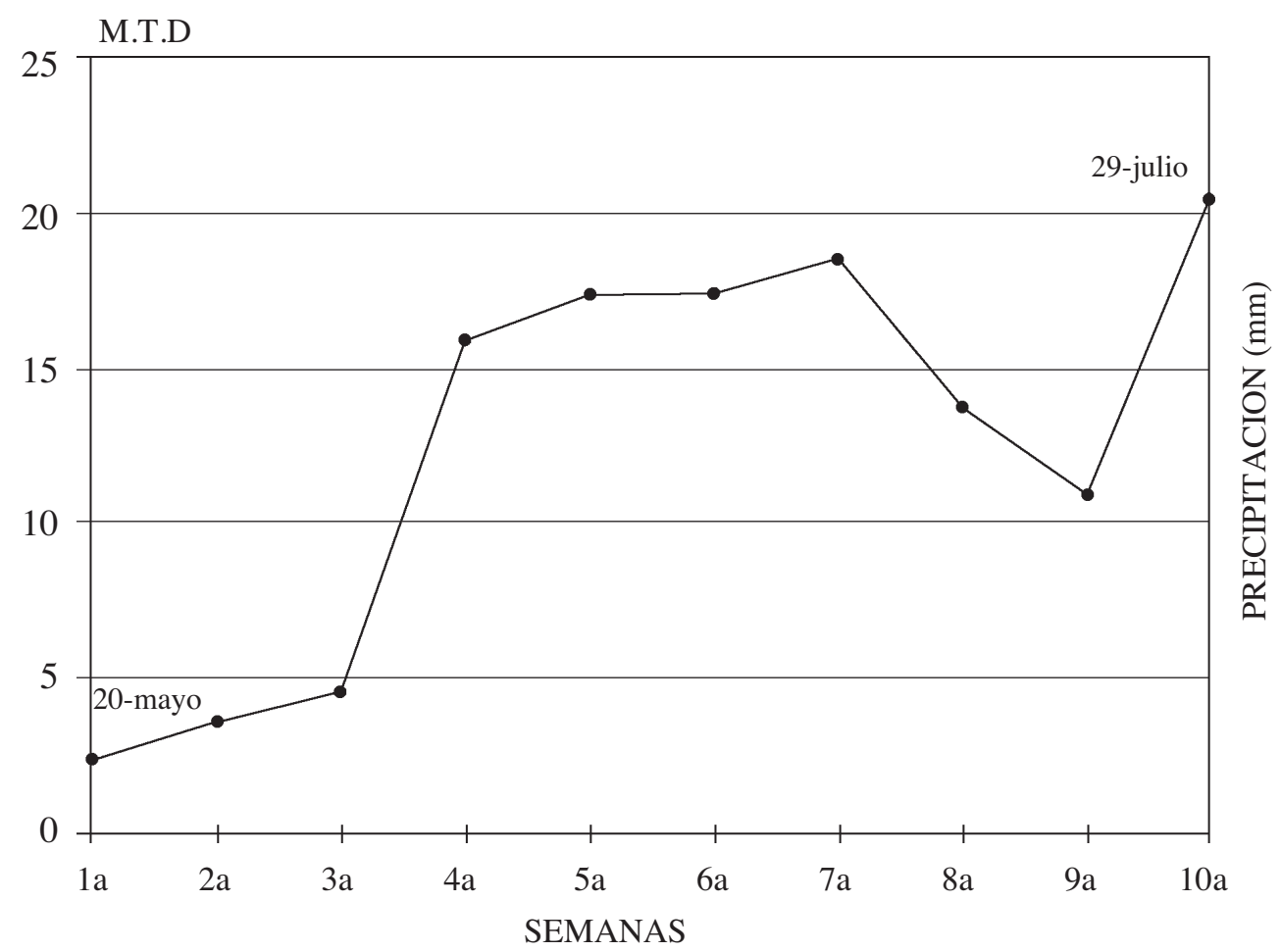

Fig. 8. Promedio por semana de las capturas diarias de Anastrepha spp. utilizando Jugo de naranja. Fca. Maravi. mayo-julio 94. 


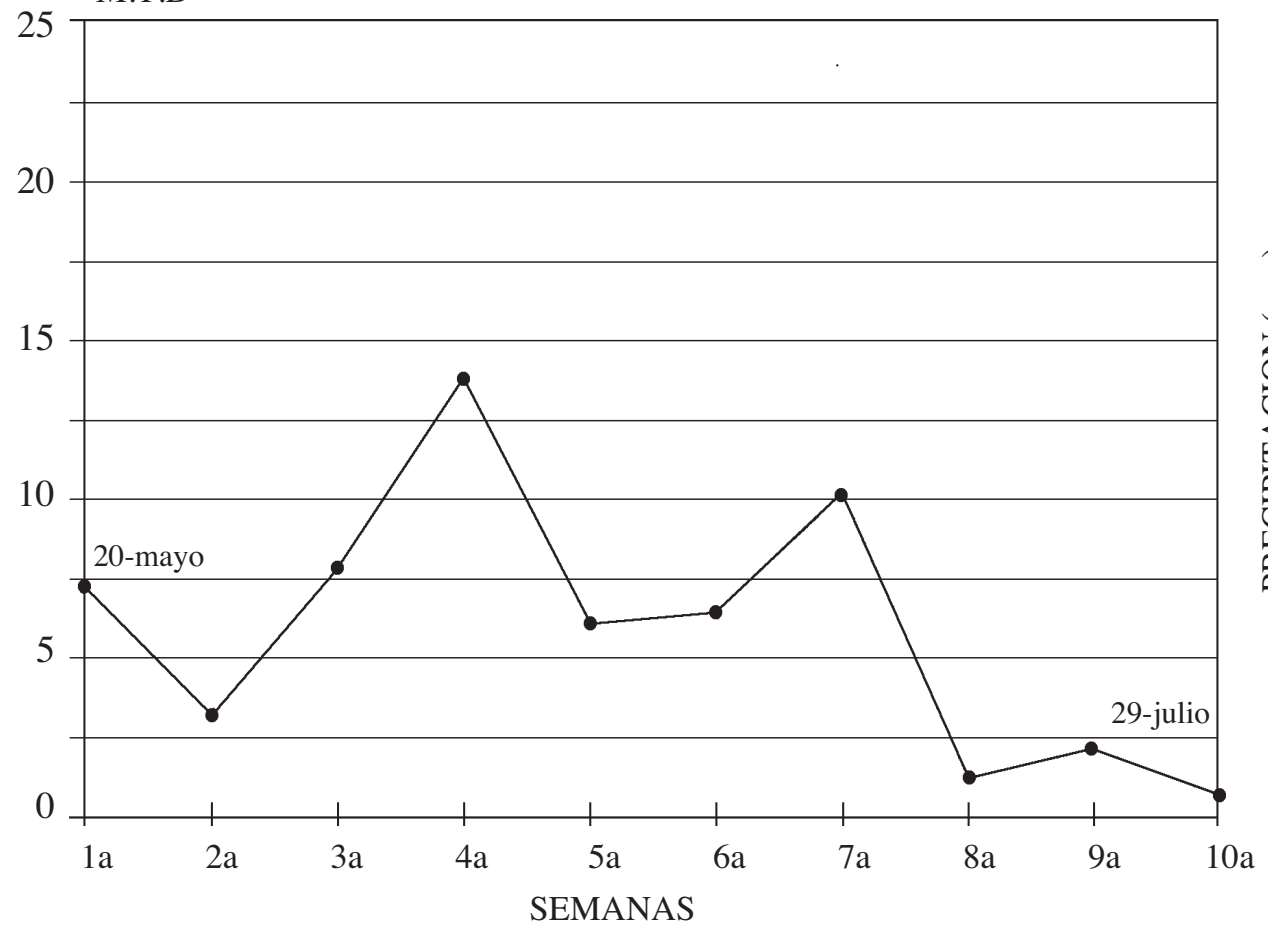

Fig. 9. Promedio por semana de las capturas diarias de Anastrepha spp. utilizando Proteína hidrolizada. Fca. Maravi. El Salvador. mayo-julio 94.

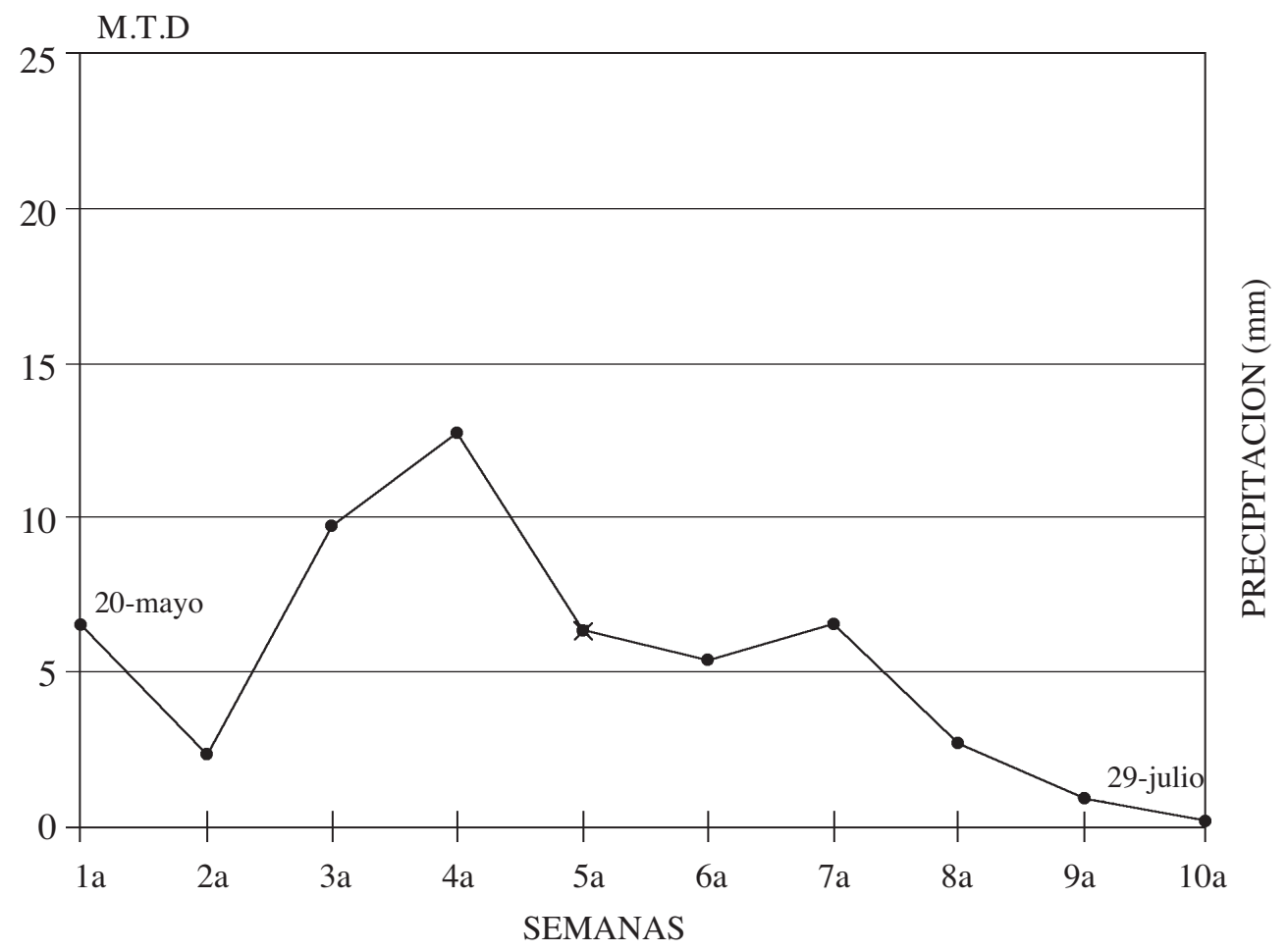

Fig. 10. Promedio por semana de las capturas diarias de Anastrepha spp. utilizando Urea. Fca. Maravi. El Salvador. mayo-julio 94. 


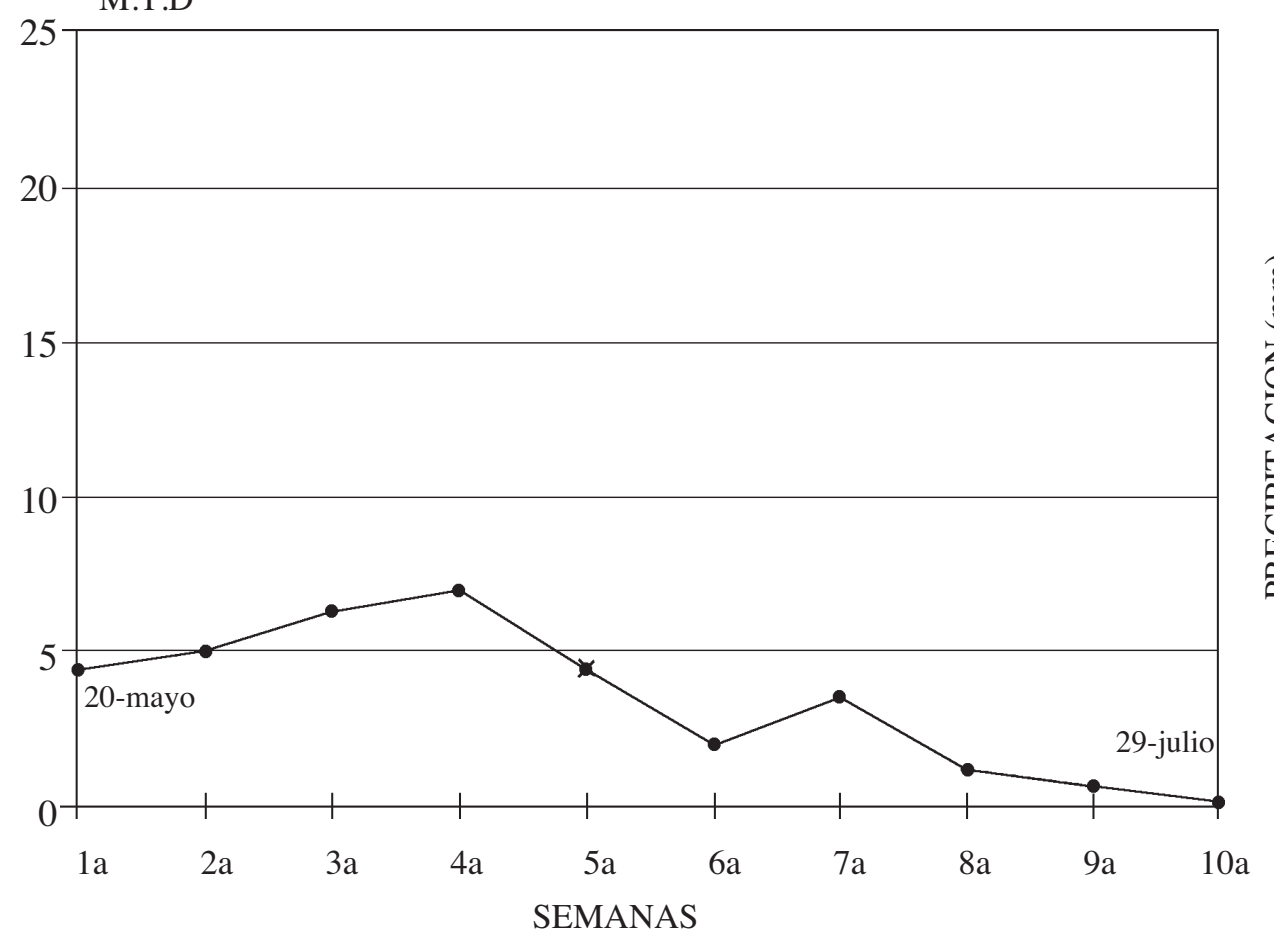

Fig. 11. Promedio por semana de las capturas diarias de Anastrepha spp. utilizando Mox. Fca. Maravi. El Salvador. mayo-julio 94.

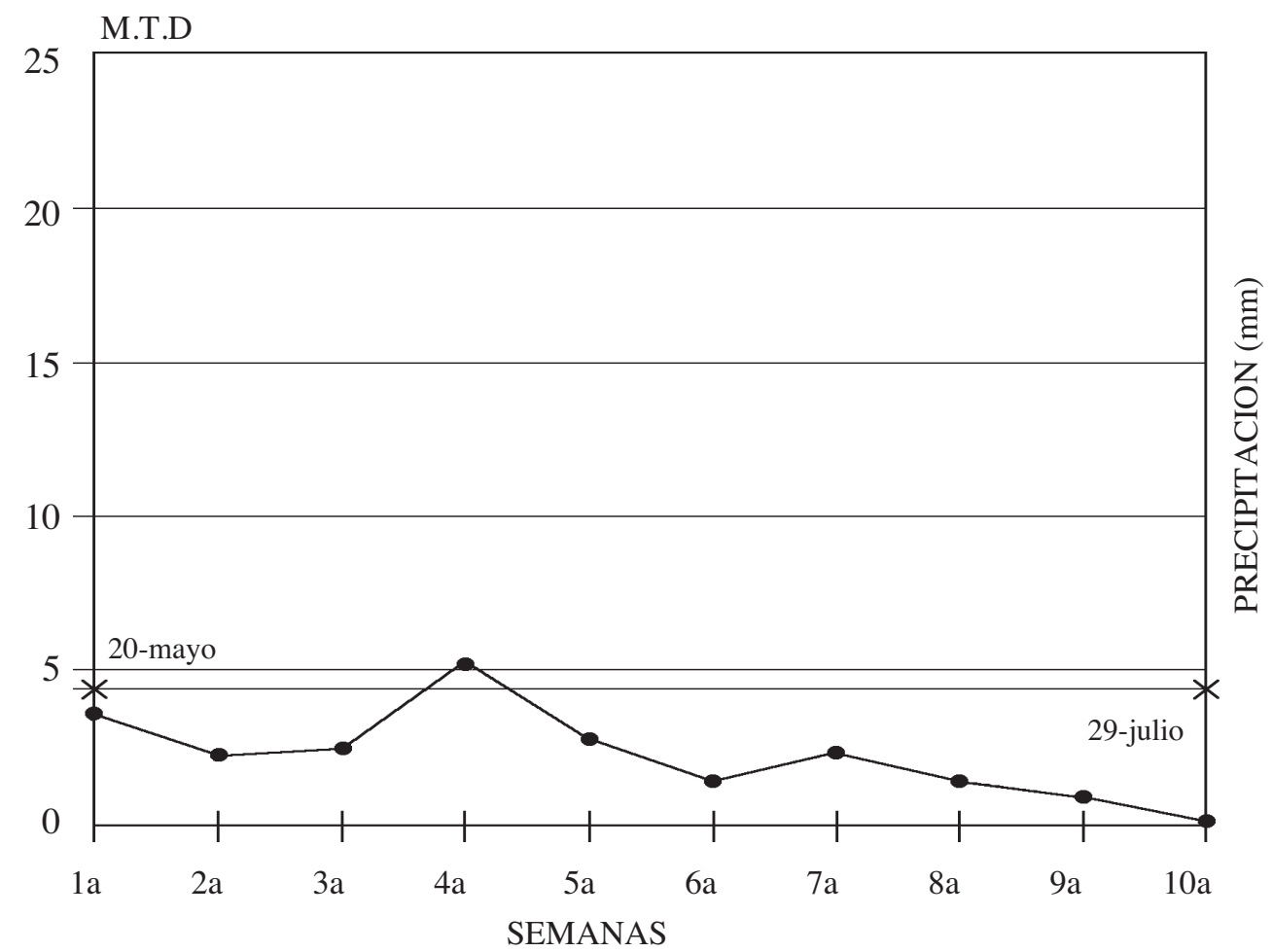

Fig. 12. Promedio por semana de las capturas diarias de Anastrepha spp. utilizando Sulfato de amonio. Fca. Maravi. El Salvador. mayo-julio 94. 
séptima semana donde el valor fue de 18,5 de MTD. En la octava. y novena semana disminuyeron un poco estos valores, alcanzando el mayor índice de captura la última semana de exposición (MTD : 20,4 ).En las trampas con jugo de naranja, a los pocos minutos se posaban hembras y machos de moscas sobre su superficie y algunos ejemplares se observaron dentro de la trampa, lo que demuestra la rápida respuesta de las especies de Anastrepha a la atracción del producto.

Con la proteína hidrolizada, la urea, el mox y el sulfato de amonio, el mayor índice de captura se alcanzó en la cuarta semana, luego disminuyen gradualmente las capturas en la quinta y sexta semana y se incrementan nuevamente en la séptima semana, disminuyendo poco a poco en las últimas semanas. Durante el período que duró el estudio (mayo-julio) siempre hubo disponibilidad de frutos de variedades de naranja, mandarina y guayaba, lo cual influyó en las capturas de las diferentes especies de Anastrepha.

\section{CONCLUSIONES}

1. El jugo de naranja resultó ser el atrayente alimenticio más eficiente de todos los productos evaluados, capturando 4,9 veces más moscas de la fruta que con la proteína hidrolizada (líquida). La proteína hidrolizada (líquida) y la urea resultaron también con índices de captura altos.

2. Con el jugo de naranja se capturaron ocho especies de Anastrepha, siendo las más abundantes A. ludens seguida por A. distincta y A. obliqua.

3. Del 5792 adultos capturados el $54,3 \%$ fueron hembras y el 45,7\% machos.

4. La relación más alta de hembra/macho se obtuvo con sulfato de amonio $(1,78: 1)$ y con urea $(1,49: 1)$.
5. Las capturas de moscas, tanto hembras como machos, fueron aumentando semanalmente a partir de la tercera semana y sus poblaciones fluctuaron según lo observado con base en la disponibilidad de frutos y a la precipitación pluvial existente.

\section{LITERATURA CITADA}

ALUJA, M; SCHUNEMAN. 1993. Manejo integrado de la mosca de la fruta, México, trillas $251 \mathrm{p}$.

BUSTILLO, A.; LONDOÑO, M.; LOPE, D. 1989. Evaluación de proteínas hidrolizadas para la detección de Ceratitis capitata en trampas McPhail en cultivos de cafeto en Antioquía, Guatemala, IICA. 10 p.

CENTRO INTERNACIONAL DE CAPACITACION EN MOSCAS DE LA FRUTA. 1992. VI Curso internacional de capacitación en moscas de la fruta. Programa Moscamed. Chiapas, México, sp.

CENTRO INTERNACIONAL DE CAPACITACION DE MOSCAS DE LA FRUTA. 1993. Curso regional de manejo integrado de moscas de la fruta. Programa Moscamed, Chiapas, México 24 p.

DIRECCION GENERAL DE SANIDAD VEGETAL Y ANIMAL 1994. Distribución geográfica de especies de moscas del género Anastrepha en El Salvador MAG. Proyecto : Programa de Sanidad Vegetal. El Salvador. 20 p.

DIRECCION GENERAL DE SANIDAD VEGETAL Y ANIMAL. 1995. Guía para el control de moscas de la fruta. MAG. Proyecto: Programa de Sanidad Vegetal. El Salvador, $23 \mathrm{p}$.

SECRETARIA DE AGRICULTURA Y RECURSOS HIDRAULICOS. 1992. Manual para el control integrado de moscas de la fruta. Dirección General de Sanidad Vegetal, México 34 p. 